\title{
PAPER
}

\section{A sensitive radioimmunoprecipitation assay for assessing the clinical relevance of antibodies to IFN $\beta$}

\author{
N Lawrence, J Oger, T Aziz, J Palace, A Vincent
}

See end of article for

J Neurol Neurosurg Psychiatry 2003;74:1236-1239

authors' affiliations

$\ldots \ldots \ldots \ldots \ldots \ldots \ldots$ Background: Some multiple sclerosis (MS) patients treated with interferon beta (IFN $\beta$ ) develop anti-

Correspondence to:

Dr A Vincent

Neurosciences Group,

Weatherall Institute of

Molecular Medicine, John

Radcliffe Hospital, Oxford,

OX3 9DS, UK;

angela.vincent@

imm.ox.ac.uk

Received

13 January 2003;

Revised version received

3 March 2003 .

Accepted for publication

4 March 2003

bodies to the drug. Neutralising antibody (NAB) assays for IFN $\beta$ are expensive and the clinical relevance of the results has been debated.

Objective: To establish a cheap, sensitive, and reliable assay for antibodies to ${ }^{125}$ IFN $\beta$, and to correlate levels of antibodies with clinical response to IFN $\beta$ treatment.

Methods: We established a radioimmunoprecipitation assay (RIPA) using ${ }^{125} \mathrm{IIFN} \beta$. We tested NAB positive sera, healthy control sera, and serial samples of 33 IFN $\beta-1 b$ treated MS patients from the Vancouver cohort of the Berlex pivotal trial who had a high incidence of NABs.

Results: We found that the RIPA was highly sensitive for the detection of antibodies to IFN $\beta$-1 a and $-1 b$, and that there was a strong correlation between reactivity of NAB positive sera for ${ }^{125} \mathrm{I}-\mathrm{IFN} \beta-1 \mathrm{~b}$ and for ${ }^{125}$ IIFN $\beta$-1 1 . The RIPA was more sensitive and consistent than the NAB. Moreover, there was a trend towards poorer MRI outcomes in RIPA positive patients, but not in NAB-positive patients.

Conclusions: The RIPA assay is sensitive and easy to perform. It should be of value in assessing the clinical impact of IFN $\beta$ antibodies, and its use could help target expensive INF $\beta$ treatments to those who will respond best.

$\mathrm{T}$ reatment with interferon beta (IFN $\beta$ ) reduces clinical attacks and MRI lesions in multiple sclerosis (MS). ${ }^{12}$ Some patients develop antibodies against IFN $\beta,^{3-5}$ and an association between neutralising antibodies (NAB) and reduced efficacy has been reported. ${ }^{45}$ However, NABs have high intra-assay and inter-laboratory variability, ${ }^{3}$ they tend to oscillate from positive to negative, and do not detect all antibodies that will reduce the bioavailability of the drug in vivo. Moreover, there are difficulties in obtaining the serological and clinical data on individual cases, making it difficult to assess therelevance of the NABs. Weestablished a radioimmunoprecipitation assay (RIPA) for binding antibodies to IFN $\beta$ - Ib and -la, compared the results with those of the NAB assay, and correlated the results with clinical efficacy in a small cohort of patients for whom detailed clinical data were available. Preliminary results have been reported in abstract form. ${ }^{6}$

\section{METHODS \\ Clinical samples}

Sera came from two sources. NAB positive sera of known antibody titre were donated by Biogen UK and by Schering UK; no clinical data were available on these sera. Clinical data were available on sera from 50 individuals from the Vancouver cohort of the pivotal trial of IFN $\beta$-lbl. Thirty three had received active therapy (Betaseron, Berlex, Richmond, CA, USA; 17 on 1.6 MIU and 16 on 8 MIU of IFN $\beta$ - $1 \mathrm{~b}$ ) subcutaneously on alternate days for 2 years; 17 were on placebo. Serum samples were taken at each visit, coded, and stored at $-80^{\circ} \mathrm{C}$. The total number of clinical attacks, the number of new or enlarging lesions, and the total lesion volume were recorded at baseline and every six weeks as previously reported.

\section{RIPA for IFN $\beta$ antibodies}

$10 \mu \mathrm{g}$ of IFN $\beta$-lb (Berlex Biosciences, Richmond, CA, USA) or IFN $\beta$-la (Ares-Serono International, Geneva) were iodinated with ${ }^{125} \mathrm{I}$ (from Amersham, UK) using chloramine $\mathrm{T}$, as previously described for botulinum toxin. ${ }^{7}$ The ${ }^{125}$ I-IFN $\beta$ s were then separated from free ${ }^{125} \mathrm{I}$ by gel filtration, filter sterilised, and stored at $+4^{\circ} \mathrm{C}$. Routinely, $10 \mu \mathrm{l}$ of ${ }^{125}$ I-IFN $\beta$ (50 000 total cpm) was incubated with $5 \mu \mathrm{l}$ of serum in $50 \mu \mathrm{l} 0.02 \mathrm{M}$ phosphate buffer $\mathrm{pH} 7.2 / 0.1 \%$ triton X-100 (PTX buffer), for 2 hours at room temperature. 50-100 $\mu \mathrm{l}$ of sheep anti-human Ig G (The Binding Site, Birmingham, UK) was added (diluted 1:4 in PTX; the actual amount used was that required to form a visible precipitate with $5 \mu \mathrm{l}$ of a range of human sera) and the precipitates centrifuged, washed in PTX, and counted on a gamma counter (Packard, Berkshire, UK). The mean value of three healthy sera was subtracted, and the results expressed as a percentage of the value obtained with a known high positive serum.

NABs were measured using the myxovirus associated antigen (MxA; by Berlex laboratories, CA, USA) on samples found to be positive by ELISA, as part of the IFN $\beta$ - $1 \mathrm{~b}$ pivotal trial. ${ }^{4}$ The MxA is a bio-assay that measures IFN $\beta$ stimulated production of human IFN type I by a carcinoma cell line (A549). The neutralising effect of sera can be tested by preincubating the IFN $\beta$ with the serum before performing the assay. The neutralisation titre is the reciprocal dilution of serum that reduces by 10 -fold the MxA inducing activity of IFN $\beta$. Positivity was defined as a NAB value of greater than 20 on two consecutive occasions.

\section{RESULTS}

\section{Establishment of a RIPA for antibodies to IFN $\beta$}

We first tested healthy controls and known NAB positive sera (NAB > 20 units) from IFN $\beta$-lb treated patients. Sera with high values showed a linear relationship of precipitation at serum amounts below around $1.5 \mu \mathrm{l}$ (Fig la), but for routine screening we used $5 \mu \mathrm{l}$. Based on the mean +3 SD of 41 healthy control data, a cut off for negative values was defined as $<5 \%$ of the maximum ${ }^{125}$ I-IFN $\beta$-lb precipitated by a high

Abbreviations: IFN $\beta$, interferon beta; $M S$, multiple sclerosis; $M \times A$, myxovirus associated antigen; NAB, neutralising antibody; RIPA, radioimmunoprecipitation assay 

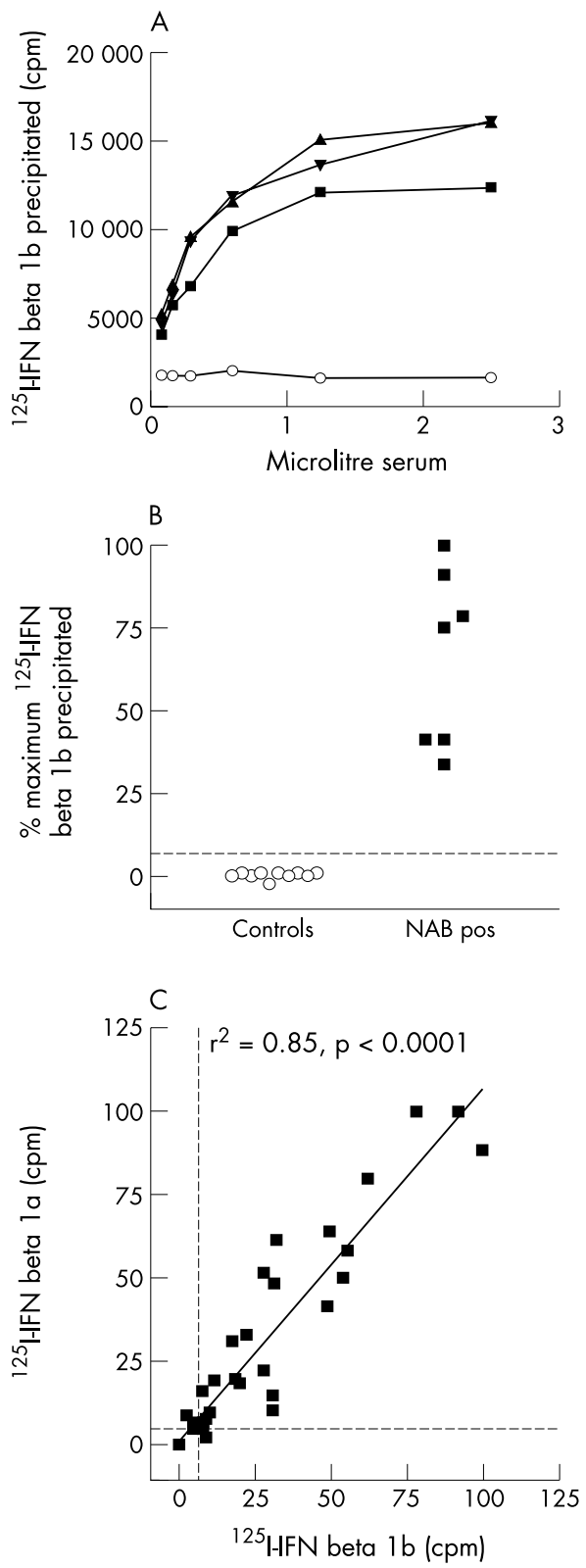

Figure 1 (A) Antibodies to IFN $\beta$ measured by immunoprecipitation of ${ }^{125}$-IFN $\beta$ illustrated for three neutralising antibodies (NAB) positive patients and one healthy control at different serum concentration. (B) In 10 sera from healthy individuals, and seven from IFN $\beta$ treated patients with known high NAB levels. (C) Antibodies to ${ }^{125}$-IFN $\beta$-1 b also bind to ${ }^{125}$-IFN $\beta$ - la by immunoprecipitation.

positive serum (as in fig la). All seven NAB positive sera immunoprecipitated ${ }^{125}$ I-IFN $\beta$-lb (Fig lb). We then tested NAB positive sera, from patients treated with IFN $\beta$ - Ib or IFN $\beta$-la, against both ${ }^{125}$ I-IFN $\beta$-lb and ${ }^{125}$ I-IFN $\beta$-la. There was a highly significant correlation of the results of the two assays ( $p<0.0001$ ), indicating that antibodies to one form of IFN generally bind well to the other (fig lc).

\section{IFN $\beta$ - $1 \mathbf{b}$ antibodies in patients in the pivotal trial}

We examined the NAB and RIPA levels in sera from patients at one year into the pivotal trial. All patients on placebo remained negative throughout (Fig $2 \mathrm{a}$ and $2 \mathrm{~b}$ ). With both assays, the antibodies were a little higher, and there were more positive results, in the patients given the lower dose of IFN $\beta$, as in other studies, ${ }^{8}$ but the difference was not signifi-
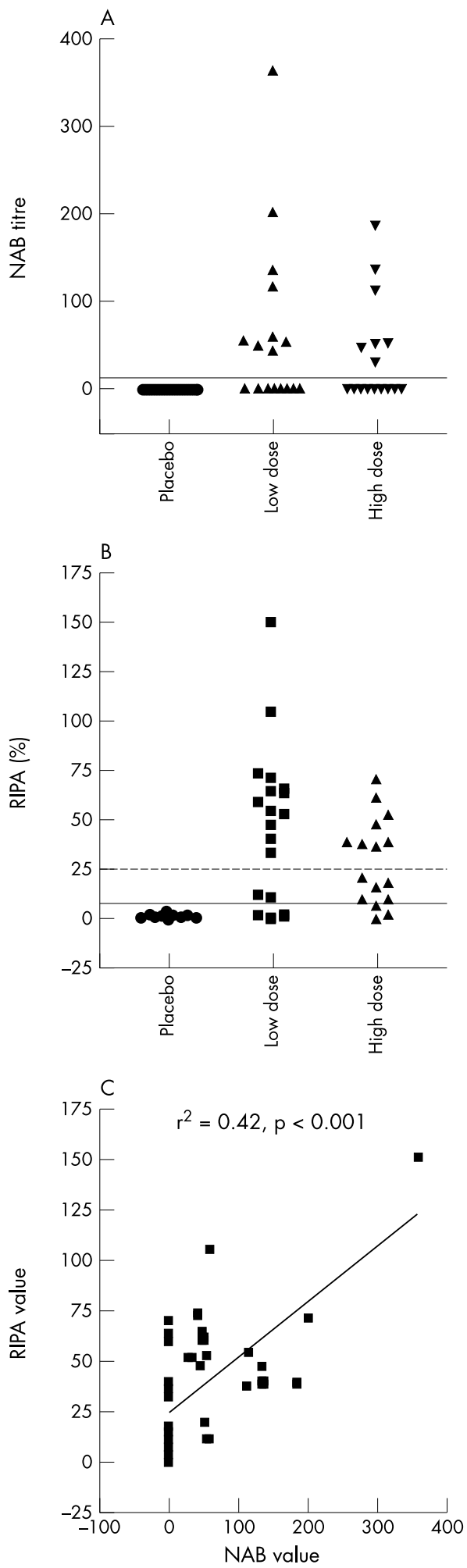

Figure 2 Antibodies to IFN $\beta$. (A) Neutralising antibodies (NAB) (B) Radioimmunoprecipitation values (RIPA) in patients treated with placebo or either 1.6 (low dose) or 8.0 (high dose) MIUs of IFN $\beta-1 \mathrm{~b}$. Correlation between the results of the two assays.

cant. Only 5/33 of the patients treated in this cohort of betaseron treated patients were negative with both assays at one year. There was a weak correlation between the values in the two assays $\left(r^{2}=0.42, p<0.001\right.$; fig $\left.2 c\right)$, but 12 IFN $\beta$ - lb treated patients who were persistently NAB negative were 

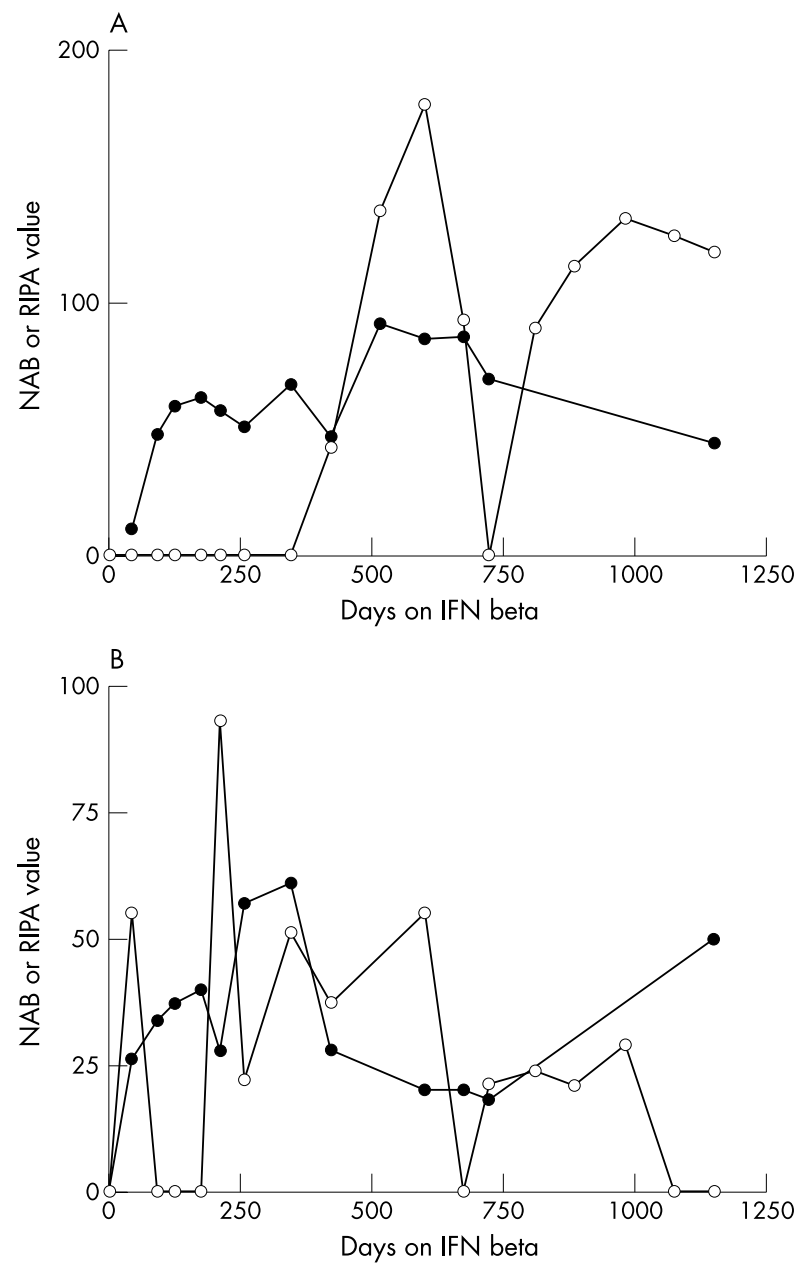

Figure 3 Serial data for NAB (open circles) and RIPA assays (closed circles) showing the time course of serum antibody levels in two representative patients $((A)$ and $(B))$.

RIPA positive, whereas none of the RIPA negative sera were NAB positive. Thus, the RIPA is more sensitive than the NAB assay.

Positive RIPA values were first detected between one and four months after starting treatment; $26 / 33$ were positive by six months, 29/33 by 12 months; and 27/33 were still positive at 24 months. RIPA values did not oscillate markedly over time (fig 3a and 3b), although there was a tendency for values to decrease in some patients (eg fig 3a). Positive NAB values were first detected between 1.5 and 13 months after starting treatment, but in some cases they oscillated between positive and negative (fig 3a and 3b), and only eight sera were positive on two consecutive occasions by six months of treatment.

Because the distribution of positive results with the RIPA was broadly bimodal (fig 2 b), we set an arbitrary level of $25 \%$ as a cut off between high and low/negative RIPA values (dotted line in fig 2b). With this cut off 21,18 , and 14 sera out of 33 treated patients had high values at 6, 12, and 24 months, respectively. The two year clinical outcomes of the pivotal trial patients were assessed in the placebo and IFN $\beta$-lb treated patients, dividing patients according to their one year antibody results (fig 4). There was the expected reduction in new or extending MRI lesions in the treated patients, but no difference between RIPA and NAB positive and negative patients (fig 4a). There was no difference between NAB positive and negative patients, with respect to increase in MRI lesion volume $(p=0.23)$. However, there was a trend towards a lower percentage increase in MRI lesion volume in the RIPA
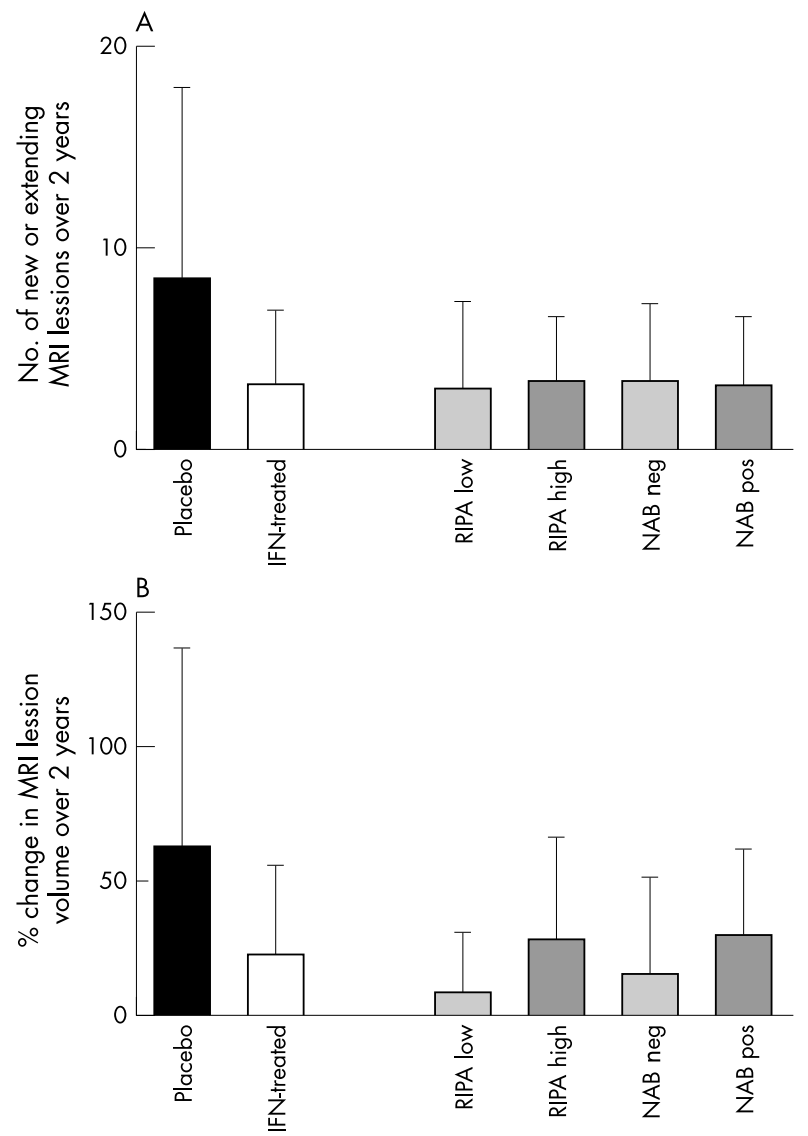

Figure 4 Clinical outcomes at two years in placebo and IFN $\beta$ treated patients. (A) The number of new and extending lesions were lower in IFN $\beta$ treated patients, but there was no influence of antibody positivity. (B) The percentage change in MRI lesion volume over two years was reduced in IFN $\beta$ treated patients, and there was a trend towards lower values in patients with low/negative RIPA values compared to those with high RIPA values. Mean + SD

low/negative group compared with the RIPA high positive group (fig $4 b ; p=0.08$ ).

\section{DISCUSSION}

We established a simple radioimmunoprecipitation assay that is highly sensitive and can be used for measuring antibodies to either IFN $\beta$-lb or IFN $\beta$-la. When we studied sera from patients who were treated with IFN $\beta$-lb as part of the pivotal trial, we found that $21 / 33$ sera had high levels of antibody by RIPA at six months into the trial (at which time only eight were positive by MxA) and remained positive thereafter, showing none of the oscillations that have been reported for various bioassays, and found here for the MxA assay. Nevertheless, the values did decrease with time in some patients, confirming results reported by others using ELISA assays. ${ }^{9-11}$

The MxA assay ${ }^{12}$ has been widely used, but it is very expensive and there are problems in determining the appropriate cut off level; moreover, inhibition by non-antibody serum factors could be misinterpreted as being due to specific antibody. In addition, although in vitro bioassays indicate the ability of the antibodies to prevent drug efficacy if applied at a target site, they are not informative about the ability of the antibodies to prevent the drug from accessing the site of action. Any antibody that binds to IFN $\beta$ before it reaches its target could lead to clearance of the drug from the circulation and reduce its bioavailability, irrespective of whether the antibody inhibits drug receptor interactions. Thus there are good reasons for looking for binding antibodies as we have done here. 
The RIPA is quick, technically easier than the bioassay, and should be relatively cheap. It detects antibodies earlier than the NAB assay and, because the results do not oscillate over time, it could be performed at just one time point (eg at six months or one year after starting treatment). Moreover, although our study was not powered to examine the effects of antibodies on the clinical outcome measures, the results in this small cohort of patients suggest that the RIPA may be of greater clinical relevance than the NAB.

Antibodies that neutralise the in vitro effects of a drug are expected to reduce its efficacy and yet there has been controversy regarding the clinical relevance of IFN $\beta$-b NABs. However, if one examines the results of the most robust cohorts, that is the large pivotal IFN $\beta$ trials, NABs do appear to attenuate efficacy: MRI outcomes were affected within one to two years of treatment, with an earlier effect on lesion volume increase than on lesion activity (explaining why we might not see a difference in lesion activity between antibody negative and positive patients at one year in our small series); the effects of NABs on relapse rate were delayed beyond 18-24 months; ${ }^{45}$ and the effects on disability outcomes showed a trend in favour of an effect in the PRISMS study over 4 years, reaching significance in the high dose group. ${ }^{5}$ Therefore, underpowering, lack of treatment effect, and short follow up periods are the likely explanations for difficulties in demonstrating an effect of IFN $\beta$ antibodies on the treatment efficacy.

It is difficult to assess the clinical relevance of antibodies from studies using different assays, directed against a drug that is only partially effective, in a disease that has a high level of biological variability and unpredictability. But in addition, the antibody tests have often been performed in house or sponsored by the pharmaceutical companies. Independent analysis of the antibody results with the clinical data has not been forthcoming. Previous reports suggest that there is a lower antibody rate with the use of IFN $\beta$-la products, and this is supported by our own unpublished observations (Lawrence, Palace, Vincent, 2000).

It is important that simple, cheap, and standardised antibody assays, like the RIPA, are set up by independent laboratories and that the effect on disability outcomes is clarified. One could then define those patients who are unlikely to benefit from treatment, at the same time targeting those who will benefit the most. This would allow these expensive treatments to be used in a more cost effective and ethical way.

\section{ACKNOWLEDGEMENTS}

We are most grateful to Berlex Biosciences, Richmond, Virginia, for the gift of Betaseron and NAB antibody positive sera, to Ares-Serono International, Geneva, for the gift of Rebif, and to Biogen UK and
Schering UK for NAB antibody positive sera. The study was made possible by a grant from Berlex Canada to JO. NL was supported in part by donations from Serono UK and Biogen UK.

\section{Authors' affiliations}

N Lawrence, A Vincent, Neurosciences Group, Weatherall Institute of Molecular Medicine, John Radcliffe Hospital, Oxford, UK

J Oger, T Aziz, Department of Neurology, University of British Columbia, Vancouver, BC, Canada

J Palace, Department of Clinical Neurology, Oxford, OX3 9DS, UK

Competing interests: In addition to financial support for clinical and laboratory staff by way of research grants, JO, JP, and AV have variously received from Berlex Canada, Serono, Biogen, Schering, and Teva Marion reimbursements for attending conferences, speaker's fees, fees for organising education, and consulting fees

\section{REFERENCES}

1 IFN $\beta$ Multiple Sclerosis Study Group. Interferon beta-b is effective in relapsing-remitting multiple sclerosis. I Clinical results of a multicenter, randomized, double-blind, placebo controlled trial. Neurology 1993:43:655-61.

2 PRISMS (Prevention of Relapses and Disability by Interferon beta- la Subcutaneously in Multiple Sclerosis) Study Group. Randomized double-blind placebo-controlled study of interferon beta- $1 \mathrm{a}$ in relapsing/remitting multiple sclerosis. Lancet 1998;352(9139): 1498504.

3 Pungor E, Files JG, Gabe JD, et al. A novel bioassay for the determination of neutralizing antibodies to interferon beta-1 b. J Interferon Cytokine Res 1998;18:1025-30

4 IFN $\beta$ Multiple Sclerosis Study Group. The UBC MS/MRI analysis: neutralizing antibodies during treatment with interferon beta- $1 \mathrm{~b}$. Neurology 1996;47:889-94.

5 PRISMS Study Group and the UBC MS/MRI Analysis Group PRISMS-4: long term efficacy of interferon-Beta la in relapsing MS. Neurology 2001;56:1628-36.

6 Palace J, Oger J, Vincent A. A new assay for antibodies to interferon-b during treatment of multiple sclerosis [Abstract]. J Neurol Neurosurg Psychiatry 1999:67:272.

7 Palace J, Nairne A, Hyman $N$, et al. A radioimmuno-precipitation assay for antibodies to botulinum A. Neurology 1998;50:1463-6.

8 Kivisakk P, Alm GB, Fredrikson S, et al. Neutralizing and binding anti-interferon beta (IFN-beta) antibodies. A comparison between IFN betal- $1 \mathrm{a}$ and IFN beta- $1 \mathrm{~b}$ treatment in multiple sclerosis. Eur J Neurol 2000; 7: 27-34

9 Perini P, Facchinetti A, Bulian P, et al. Intereferon-beta antibodies in interferon beta $1 \mathrm{a}$ and interferon beta $\mathrm{lb}$-treated multiple sclerosis patients. Prevalence, kinetics, cross-reactivity and factors enhancing interferon beta immunogenicity in vivo. Eur Cytokine Netw 2000;12: 56-61

10 Rice GP, Paszner B, Oger J, et al. The evolution of neutralizing antibodies in multiple sclerosis patients treated with interferon beta $\mathrm{lb}$. Neurology 1999;52:1277-9.

11 Rudick RA, Simonian NA, Alam JA, et al. Incidence and significance of neutralizing antibodies to interferon beta-la in multiple sclerosis. Multiple Sclerosis Collaborative Research Group (MSCRG). Neurology 1998:50:1266-72.

12 Files J, Gray J, Do L, et al. Novel Sensitive and Selective Bioassay for Human Type I Interferons. J Interferon and Cytokine Research 1998; 18:1019-24. 